\title{
EFFECT OF PHOTIC STIMULATION ON ACETYLCHOLINE RELEASE FROM CAT CEREBRAL CORTEX*
}

\author{
A. Bartolini, $\dagger$ L. M. Weisenthal $\ddagger$ and E. F. Domino \\ Neuropsychopharmacology Research Program, Department of Pharmacology, \\ University of Michigan, Ann Arbor, Michigan 48104
}

(Accepted 7 May 1971)

\begin{abstract}
Summary-Cortical release of acetylcholine was assayed using the leech muscle preparation in cats with transected brainstems. Both spontaneous and elicited somatosensory and visual cortical release of acetylcholine were measured, photic stimuli being directed into both eyes of midpontine-pretrigeminal and prepontine preparations. Animals with midpontine transections had a higher spontaneous release of acetylcholine from the visual cortex than did prepontine animals, but photic stimulation did not increase acetylcholine release. The prepontine cats tended to show an increase in cortical release of acetylcholine to photic stimulation which was not statistically significant. After injections or topical application of scopolamine, spontaneous and elicited release of acetylcholine was markedly increased. Thus, photic stimulation of the retinae did not markedly increase acetylcholine release, either with or without scopolamine treatment, and the evoked release of acetylcholine from the visual cortex was similar to that from the sensorimotor cortex. Differences in acetylcholine release between cats with "activated" and "synchronized" EEGs were demonstrated before and after scopolamine. The content of acetylcholine in the motorsensory, somatosensory, auditory and visual cortices varied, with the lowest in the somatosensory and the highest in the visual area. In contrast, the release of acetylcholine was higher in the somatosensory than in the visual area, suggesting that the former has a higher turnover rate of acetylcholine. The data suggest that acetylcholine is not released from primary visual afferent fibers, but rather from neurons involved in a diffuse brainstem activating system.
\end{abstract}

A CONSIDERABLE amount of data dealing with the cortical release of acetylcholine (ACh) has been published since the pioneer studies of Elliort et al. (1950) and MacINTOSH and OBORIN (1953). Most investigations have been carried out on anesthetized animals (Mitchell, 1963; Mclennan, 1964; PolaK, 1965; Beleslin and PolaK, 1965; Beleslin et al., 1965; KaNAI and Szerb, 1965; Collier and Mitchell, 1966, 1967; Szerb, 1967; Phillis, 1968; Neal et al., 1968; Dudar and Szerr, 1969; Hemsworth and Mrtchell, 1969). Other investigators have used unanesthetized animals immobilized by means of brainstem transections (Sie et al., 1965; Phillis and ChONG, 1965; Bartolini and PePEu, 1967, 1970; PePEU and BARTolini, 1968) or by means of curare-like drugs (SzERB, 1964; CELESIA and JASPER, 1966). More recently, chronic conscious preparations have been used (Collier and Mitchell, 1967; BeANi et al., 1968).

COLLIER and MITCHELL $(1966,1967)$ have shown in rabbits anesthetized with allobarbitalurethane that constant retinal illumination released a large amount of $\mathrm{ACh}$ from the

\footnotetext{
*Supported in part by Grant MH-11846, USPHS.

$\dagger$ Italo-American exchange research fellow from the Department of Pharmacology, University of Florence. Awarded a grant under the mutual education and cultural exchange Fulbright-Hays Act and the Italian National Council of Research. $\ddagger$ Predoctoral trainee, USPHS 5T01-GM00198.
} 
primary visual cortex and less from other cortical areas. PhILLIs (1968) has also shown in cats anesthetized with various agents that visual stimulation effects the release of cortical ACh. Inasmuch as anesthesia lowers the basal cortical release of ACh (MACINTOSH and Oborin, 1953; Mitchell, 1963; Pepeu and Bartolini, 1968), it seemed worthwhile to reinvestigate the cortical release of $\mathrm{ACh}$ in cats with brainstem transections under posthalothane anesthesia, both in the absence and presence of scopolamine. The content of $\mathrm{ACh}$ in several cortical areas was also determined and an attempt was made to relate these findings with those on $\mathrm{ACh}$ release.

\section{METHODS}

In the release experiments, surgery was performed on adult cats under halothane anesthesia. The atlanto-occipital membrane was opened to allow free drainage of the cerebrospinal fluid. A stereotaxically oriented spatula was used for transections which were made at either the midpontine-pretrigeminal or at the prepontine-collicular level. Shortly after transection, the skull was opened over a large part of the frontoparietal and occipital areas. The cats were allowed to recover from the halothane anesthesia for 3 hr. During this time they resumed spontaneous respiration. Body temperature was maintained as close to $37^{\circ} \mathrm{C}$ as possible and was monitored by a rectal probe. The collecting cups were constructed according to Mitchell (1963). After opening the dura, a round perspex cylinder covering $0.33 \mathrm{~cm}^{2}$ of the cortex was lowered onto the sensorimotor area with the aid of an adjustable electrode carrier. An elliptical perspex cylinder, covering $0.25 \mathrm{~cm}^{2}$ of the cortex, was then lowered onto the primary visual area. This was localized as that area of the marginal gyrus from which the best evoked potentials were recorded in response to retinal photostimulation. The cylinders were filled with $0.25 \mathrm{ml}$ of a Ringer's medium containing (concentration in $\mathrm{g} / \mathrm{l}$.) : $\mathrm{NaCl}, 9 ; \mathrm{KCl}, 0.42 ; \mathrm{CaCl}_{2}, 0.24 ; \mathrm{NaHCO}_{3}$, 0.5 ; glucose, 1 ; and physostigmine sulfate, $0 \cdot 1$. Every $15 \mathrm{~min}$ the solutions were aspirated from the collecting cups and immediately bioassayed for $\mathrm{ACh}$ using the dorsal muscle of the leech according to the method of MurnaGHan (1958). The upper end of the muscle was connected to a small mirror which reflected a beam of light onto a graduated scale approximately $1.5 \mathrm{~m}$ away on the wall, allowing a 200 -fold magnification. The samples collected from the cups were diluted with distilled water (1 vol. diluted to 1.4 vol.) for the purpose of achieving isotonicity with the leech Ringer solution. The samples were then compared with standard solutions of $\mathrm{ACh} \mathrm{HCl}$ containing the same concentration of physostigmine made daily. In order to ensure that maximal cholinesterase inhibition had occurred in the area of the cortex beneath the cup, the samples from the first three 15-min intervals were not assayed. In certain parts of the experiment, Ringer's medium containing scopolamine bromide $(1 \mu \mathrm{g} / \mathrm{ml})$ was added to the cup. The presence of this drug did not affect the assay for ACh. Evidence that the substance released into the cup was either $\mathrm{ACh}$ or some very similar choline ester has been given previously (MITCHELL, 1963; SZERB, 1963; Bartolini and PEPEU, 1967).

The electrical activity of the cortex was recorded by means of screw electrodes inserted into the skull and silver ball electrodes placed inside the 2 collecting cups. An indifferent electrode was inserted in the midline of the frontal bone. The retinas of both eyes were stimulated by means of flashing light placed approximately $25 \mathrm{~cm}$ from the eyes. Photostimulation at the rate of $2.5 \mathrm{~Hz}$ was given for $15 \mathrm{~min}$. PHILlis (1968) has demonstrated that the optimal frequency for photostimulation causing ACh release lies between 0.5 and $5 \mathrm{~Hz}$. During photostimulation the eyelids and nictitating membranes were held 
open by means of mechanical supports. When photostimulation was not applied, the eyes were covered with moistened gauze. Preliminary data indicated that the cortical release of $\mathrm{ACh}$ was increased when a $0.1 \%$ solution of scopolamine was applied to both eyes. However, it was not altered during photostimulation when mydriasis was induced by $1 \%$ solution of phenylephrine. Since there appeared to be no significant difference between phenylephrine-treated and untreated animals, the latter were usually used. All cats used demonstrated good photic driving electrographically to photostimulation. Blood pressure was recorded from the femoral artery. In some experiments, scopolamine bromide $(0.75 \mathrm{mg} / \mathrm{kg})$ was injected through a polyethylene cannula inserted in the femoral vein. All experiments were carried out in a darkened laboratory. After the end of the experiment, the precise level of the brainstem transection was determined.

In the experiments for measuring ACh content, adult cats were killed by decapitation. Discrete portions (less than $100 \mathrm{mg}$ ) of motorsensory (precruciate), sensimotor (postcruciate), parietal and primary visual cortices were isolated, weighed and homogenized in a tube with a chilled mixture of $0.2 \%$ acetic acid in $95 \%$ ethyl alcohol. No longer than $5 \mathrm{~min}$ was allowed to elapse between decapitation and the onset of homogenization. The portions of visual and sensorimotor areas removed coincided exactly with those areas onto which the perspex cups were applied in the release experiment. ACh was extracted according to the method of STONe (1955) and Crossland (1961) and bioassayed the same day. Proof that the extracted substance was either $\mathrm{ACh}$ or a closely related ester was obtained in the following ways: (1) The muscle did not respond to the extract after treatment with $d$-tubocurarine hydrochloride $\left(3 \times 10^{-6} \mathrm{~g} / \mathrm{ml}\right),(2)$ the substance was stable in an acid medium, (3) boiling in an alkaline medium abolished its ability to elicit a muscle response.

\section{RESULTS}

\section{Effect of retinal photostimulation on the EEG}

In many experiments, retinal photostimulation at a frequency of $2.5 \mathrm{~Hz}$ did not produce a noticeable change in the EEG pattern except for the photic driving responses. However, a slight increase in activation following the $15-\mathrm{min}$ period of photostimulation was observed in several experiments in which a synchronized EEG had resulted from a prepontine transection. A slight increase in the ongoing level of seizure activity following the period of photostimulation was frequently noted in those cortical areas in which topical physostigmine was present in animals with a midpontine-pretrigeminal transection.

\section{Effect of retinal photostimulation on the cortical release of $A C h$ in the absence and presence of scopolamine}

Figure 1 shows the results of one experiment in which the effect of retinal photostimulation on the release of ACh from the sensorimotor and primary visual areas of the cerebral cortex was measured. Following 3 control periods in which the basal level of release was established, the retinas were stimulated at $2.5 \mathrm{~Hz}$ for $15 \mathrm{~min}$ during the fourth interval. At the beginning of the sixth interval, scopolamine was administered by either topical application to the cup or by i.v. injection. When the increased release effected by scopolamine became maximal, retinal photostimulation was repeated for one interval, and 1 or 2 samples were bioassayed subsequent to this photostimulation. The results of the individual experiments are summarized in Table 1. Individual as well as mean data are presented because of the marked variations in basal release of ACh. No 


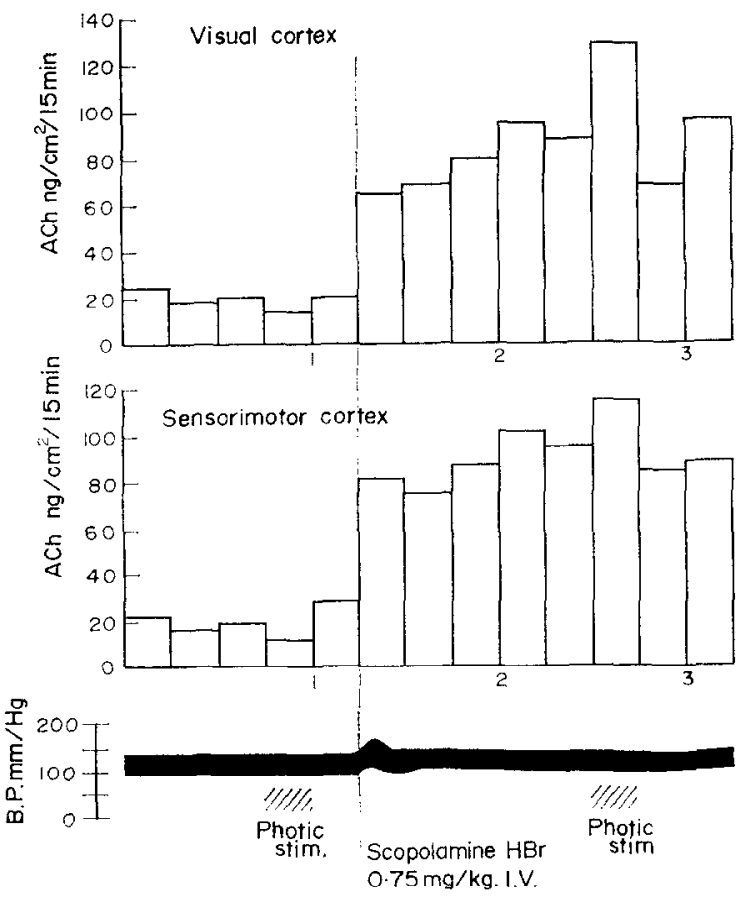

FIG. 1. Effect of photostimulation and scopolamine on cortical release of $\mathrm{ACh}$.

statistically significant change in the level of $\mathrm{ACh}$ release during photostimulation occurred in the absence of scopolamine. It is interesting to note that the release during photostimulation tended to decrease in cats with an activated EEG, while the release tended to increase in cats with a synchronized EEG. There was no significant difference between the visual and sensorimotor cortices in response to photostimulation. Following treatment with scopolamine, the activated cats did not demonstrate the slight decrease in response to photostimulation noted in the absence of scopolamine. However, in every case, cats with a synchronized EEG responded to retinal photostimulation with a more conspicuously increased release than that observed in cats with an activated EEG.

\section{The effect of scopolamine on the cortical release of $\mathrm{ACh}$}

Either topical or i.v. scopolamine markedly increased the release of $\mathrm{ACh}$ from both the visual and sensorimotor cortices. In cats with an activated EEG, scopolamine increased the release by factors of 4.3 and 3 in the visual and sensorimotor areas, respectively (Table 2). The effect of scopolamine in cats with a synchronized EEG was less pronounced, increasing the release of $\mathrm{ACh}$ by factors of $2 \cdot 3$ and $2 \cdot 1$ in the 2 areas. These values were obtained in animals deprived of most external stimulation for the experimental room was darkened and relatively odor-free. Scopolamine increased the release during photostimulation by factors of $4 \cdot 8$ (from $21 \cdot 5$ to $104 \cdot 3$ ) and $2 \cdot 7$ (from $37 \cdot 2$ to $101 \cdot 5$ ) in the visual and sensorimotor areas, respectively, of activated cats (Table 1). The release effected by scopolamine during photostimulation of cats with a synchronized EEG was 1.7 (from 18.8 to 33.4 ) and 2.6 (from 22.6 to 58.8 ) times the control values in these 2 areas. In the visual cortex, the increased release due to scopolamine was much more pronounced in 


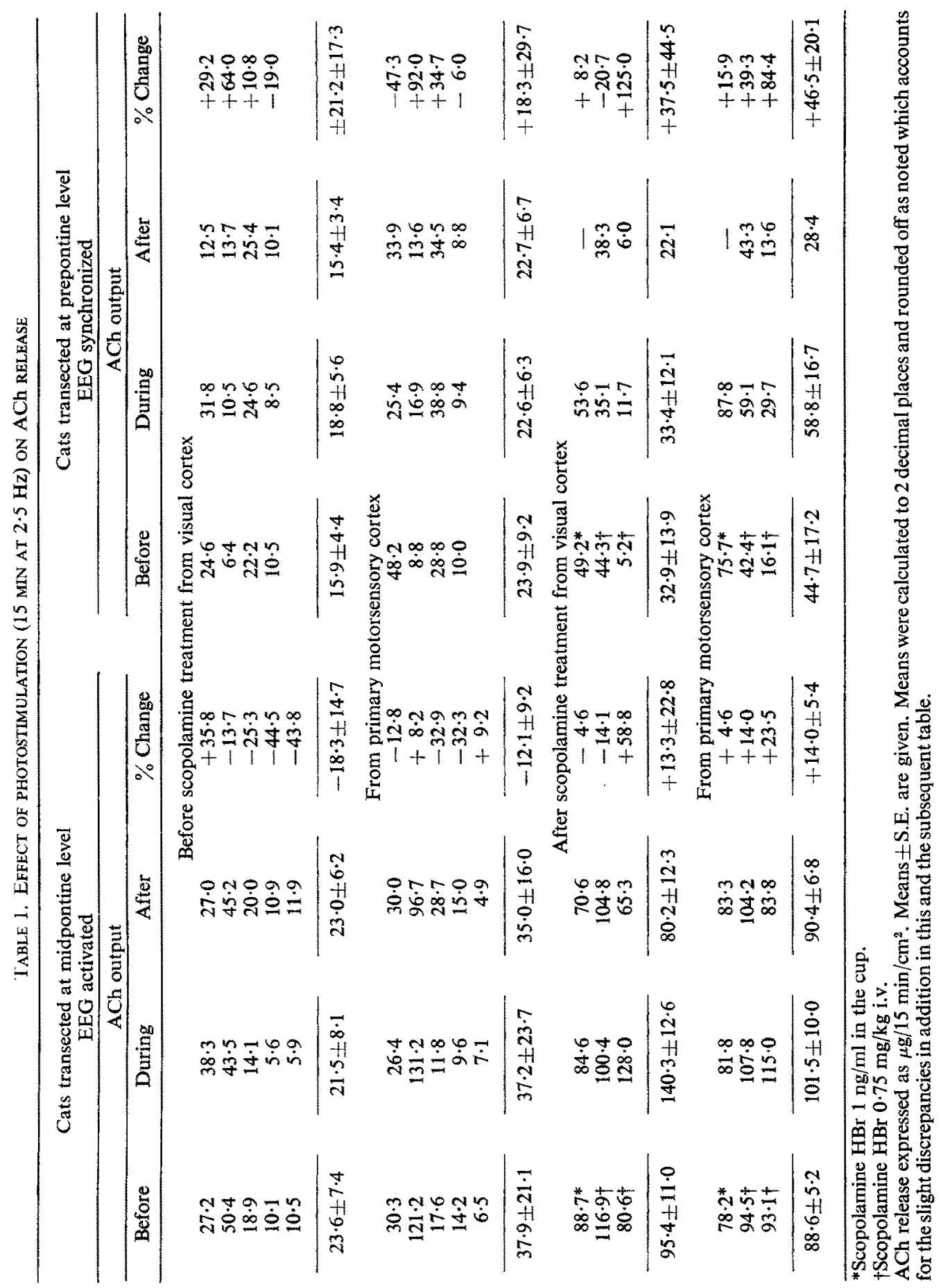


Table 2. Effect of scopolamine on ACh release

\begin{tabular}{|c|c|c|c|c|c|}
\hline \multicolumn{3}{|c|}{$\begin{array}{c}\text { Cats transected at midpontine level } \\
\text { EEG activated }\end{array}$} & \multicolumn{3}{|c|}{$\begin{array}{c}\text { Cats transected at prepontine level } \\
\text { EEG synchronized }\end{array}$} \\
\hline $\begin{array}{l}\text { Basal } \\
\text { release }\end{array}$ & $\begin{array}{l}\text { Maximum after } \\
\text { scopolamine }\end{array}$ & Ratio & $\begin{array}{l}\text { Basal } \\
\text { release }\end{array}$ & $\begin{array}{l}\text { Maximum after } \\
\text { scopolamine }\end{array}$ & Ratio \\
\hline \multicolumn{6}{|c|}{ From visual cortex } \\
\hline $\begin{array}{r}27.0 \\
45.2 \\
20.0 \\
10.9 \\
7.0\end{array}$ & $\begin{array}{r}88 \cdot 7 * \\
135 \cdot 5 \dagger \\
94 \cdot 0 \dagger \\
134 \cdot 1 \dagger \\
26 \cdot 2 \dagger\end{array}$ & & $\begin{array}{l}12 \cdot 5 \\
13 \cdot 7 \\
25 \cdot 4 \\
10 \cdot 1\end{array}$ & $\begin{array}{l}49 \cdot 2^{*} \\
24 \cdot 2^{*} \\
48 \cdot 4 \dagger \\
21 \cdot 4 \dagger\end{array}$ & \\
\hline $22 \cdot 0 \pm 6 \cdot 7$ & $95 \cdot 7 \pm 19 \cdot 9$ & $4 \cdot 3$ & $15 \cdot 4 \pm 3 \cdot 4$ & $35 \cdot 8 \pm 7 \cdot 5$ & $2 \cdot 3$ \\
\hline \multicolumn{6}{|c|}{ From primary sensory cortex } \\
\hline $\begin{array}{r}30.0 \\
96.7 \\
28 \cdot 7 \\
15.0 \\
4 \cdot 2\end{array}$ & $\begin{array}{r}90 \cdot 9 * \\
127 \cdot 8 \dagger \\
106 \cdot 9 \dagger \\
109 \cdot 6 \dagger \\
96 \cdot 2 \dagger\end{array}$ & & $\begin{array}{r}33 \cdot 9 \\
13 \cdot 6 \\
34 \cdot 5 \\
8 \cdot 8\end{array}$ & $\begin{array}{l}75 \cdot 7^{*} \\
30 \cdot 3^{*} \\
65 \cdot 4 \dagger \\
21 \cdot 8 \dagger\end{array}$ & \\
\hline $34 \cdot 9 \pm 16 \cdot 1$ & $106 \cdot 2 \pm 6 \cdot 3$ & $3 \cdot 0$ & $22 \cdot 7 \pm 6 \cdot 7$ & $48 \cdot 3 \pm 13 \cdot 1$ & $2 \cdot 1$ \\
\hline
\end{tabular}

*Scopolamine $\mathrm{HBr} 1 \mu \mathrm{g} / \mathrm{ml}$ in the cup.

† Scopolamine $\mathrm{HBr} 0.75 \mathrm{mg} / \mathrm{kg}$ i.v.

$\mathrm{ACh}$ release expressed as $\mu \mathrm{g} / 15 \mathrm{~min} / \mathrm{cm}^{2}$. Means \pm S.E. are given.

animals with an activated EEG (4.8 times with photostimulation, 4.3 times without photostimulation) than in prepontine cats with a synchronized EEG $(1.7$ times with photostimulation, 2.3 times without photostimulation). In the sensorimotor cortex, this difference in the effect of scopolamine on cats with activated and synchronized EEGs was not so dramatic. In the absence of photostimulation, the increased release due to scopolamine was more pronounced in cats with an activated EEG ( 3 times) than in cats with a synchronized EEG $(2 \cdot 1$ times). However, in the presence of photostimulation, the increased release was quite proportional to the level of release before scopolamine $(2.7$ times in cats with activated EEGs and 2.6 times in cats with synchronized EEGs). These last results are in agreement with previous experiments carried out in an illuminated room (Bartolini and Pepeu, 1967).

\section{Acetylcholine content in the visual cortex and other circumscribed cortical areas}

The ACh content of the visual, auditory, and motorsensory (precruciate) cortices was demonstrated to be nearly equivalent in control cats (Table 3). However, the ACh content of the sensorimotor area (postcruciate) was much lower, being slightly more than half of the other areas $(P<0.01)$. The level of $\mathrm{ACh}$ in all these areas was not affected by the i.p. injection of saline 15 min prior to decapitation.

Pentobarbital sodium ( $40 \mathrm{mg} / \mathrm{kg}$ ), administered i.p. $15 \mathrm{~min}$ before decapitation, effected a highly significant increase in the ACh content of the four areas studied.

\section{DISCUSSION}

All investigations, including the present one, on the cortical release of ACh have disclosed a great variability from animal to animal in the basal release of this substance. 
TABle 3. Effects of pentobarbital on the ACh Content of some cortical AREAS OF CAT BRAIN

\begin{tabular}{lccc}
\hline \multicolumn{1}{c}{ Area } & Saline $0.9 \%$ & Pentobarbital & $P$ Value \\
\hline $\mathrm{N}$ & 8 & 6 & \\
$\begin{array}{l}\text { Motorsensory } \\
\text { (precruciate) }\end{array}$ & $1 \cdot 10 \pm 0.08$ & $2 \cdot 90 \pm 0.33$ & $<0.01$ \\
$\mathrm{~N}$ & 13 & 6 & \\
$\begin{array}{l}\text { Sensorimotor } \\
\text { (postcruciate) }\end{array}$ & $0.69 \pm 0.07$ & $2.41 \pm 0.45$ & $<0.01$ \\
$\mathrm{~N}$ & 5 & 6 & \\
$\begin{array}{l}\text { Visual } \\
\text { (marginal) }\end{array}$ & $1 \cdot 20 \pm 0.13$ & $2.86 \pm 0.44$ & $<0.01$ \\
$\mathrm{~N}$ & 13 & 6 & \\
$\begin{array}{l}\text { Auditory } \\
\text { (ectosylvian) }\end{array}$ & $1.23 \pm 0.04$ & $3.65 \pm 0.40$ & $<0.01$ \\
\hline
\end{tabular}

Data expressed as mean \pm S.E.

It is well known that the addition of physostigmine into cups applied to the cortical surface will lead to the appearance of high voltage spiking from the leads in these cups in animals with an initially activated cortical EEG (BARTOLINI and PEPEU, 1967; BEANI et al., 1968). There seems to be no way in which the use of an anticholinesterase agent for experiments of this type can be eliminated. It is important to emphasize that the basal release of ACh in the same animal was always fairly constant for the duration of the experiment. Because of this, it is possible to take into consideration small variations in release which were not significant on statistical analysis of the pooled data.

A slight, statistically insignificant, decrease in ACh release was noted in cats with an activated EEG during the 15 -min period of photostimulation. It is possible that this decrease was due to a local increase in cerebral blood flow, which might diminish the amount of ACh diffusion into the cups by means of a "sink" effect. It is well known that cortical blood flow is closely correlated with cortical functional activity (RoY and SHERRINGTON, 1890; FoG, 1935; SCHMIDT and HeNDRIX, 1937; JASPER and ERICKSON, 1941 ; INGVAR, 1955, 1958; INGVAR and Soderberg, 1956; SoKolofF, 1961; INGVAR and LASSEN, 1962). Additionally, the decreased release of ACh noted during retinal photostimulation was more clearly manifest in the visual cortex, which is known to demonstrate a selectively greater increase in blood flow during retinal photostimulation (SoKOLOFF and KETY, 1960). In contrast, the small increase of ACh release that was observed in cats with a synchronized EEG in the present experiments is probably correlated with the slight EEG activation that was apparent at the end of the $15-\mathrm{min}$ photostimulation period. A correlation between cortical activation and cortical release of $\mathrm{ACh}$ has been repeatedly observed (Mitchell, 1963; KANAI and Szerb, 1965; Celesia and JASPER, 1966; BartolinI and PePeU, 1967).

It is obvious that under the same experimental conditions but without a coincident increase of the cortical blood flow, the increased output of ACh during retinal photostimulation might have been more convincing. It could be argued that such an experimental situation exists when scopolamine is present. Cerebral parasympathetic vasodilator pathways have been described (CHOROBSKI and PENField, 1932), and it is possible that these pathways are inhibited by scopolamine. Although Szerb (1964) demonstrated that the 
vascular effect of anticholinergic drugs could not account for the large effect that they have on cortical release of $\mathrm{ACh}$, the possibility remains that these vascular effects might, at least secondarily, mediate the potentiation of the effect of cortical activation on $\mathrm{ACh}$ release in the presence of these drugs. The present findings are in agreement with what DUDAR and SzERB (1969) have described as the mechanism of atropine's action. These authors affirm that the cholinergic muscarinic antagonists like atropine and scopolamine increase $\mathrm{ACh}$ cortical release by blocking the action of $\mathrm{ACh}$ on cortical neurons. Conceptually, these neurons might mediate a feedback inhibition of ascending cholinergic fibers. In the presence of scopolamine, this feedback inhibition would be reduced and ascending cholinergic activity would be increased, resulting in an increased diffusion of $\mathrm{ACh}$ into the collecting cups. This hypothesis is supported by evidence of DudAR and SzERB that atropine and scopolamine do not increase spontaneous $\mathrm{ACh}$ release. Only $\mathrm{ACh}$ release evoked by transsynaptic stimulation of cholinergic neurons is potentiated by antimuscarinic drugs.

The present results support the above hypothesis. In the nonstimulated animal the increased release of $\mathrm{ACh}$ due to scopolamine was larger in cats with an activated $\mathrm{EEG}$ than in cats with a synchronized EEG. In addition, scopolamine potentiated the slightly increased release occurring during photostimulation in cats with a synchronized EEG and reduced the decreased release during photostimulation in cats with an activated EEG. This increased release during photostimulation may be understood if we postulate that it was mediated through a concurrent slight activation of the ascending reticular system. DUDAR and SzERB (1969) have, in fact, shown that following the topical application of atropine, reticular formation stimulation was 4 times more effective in increasing $\mathrm{ACh}$ output than before atropine. On the other hand, MolenaAR and POLAK (1970) have shown that atropine increases $\mathrm{ACh}$ release and synthesis in rat brain cortical slices in vitro. Therefore, the hypothesis of BARTOLINI and PEPEU (1967) that cholinergic muscarinic antagonists increase $\mathrm{ACh}$ output through the occupation of specific $\mathrm{ACh}$ receptors or that of PolaK (1965) of a competition for ACh uptake must still be considered.

The present data indicate that animals with EEG activation associated with a high release of $\mathrm{ACh}$ from the visual cortex did not respond to photostimulation with an increased release of $\mathrm{ACh}$. In contrast, animals with a synchronized EEG and low cortical $\mathrm{ACh}$ release showed an increase in basal release with photic stimulation. In the latter experimental conditions we observed simultancous increases in the release of acetylcholine from both the visual and sensorimotor cortices. Furthermore, the increase in both these areas was of comparable magnitude. These results are in agreement with those of PHILLIS (1968). In anesthetized cats he demonstrated a comparable increase in ACh output from all the cortical areas monitored. That the present results appear to conflict with those of Collier and Mitchell $(1966,1967)$ in the anesthetized rabbit may, perhaps, be attributed to different durations of retinal stimulation. These authors obtained a large increase in $\mathrm{ACh}$ release from primary visual receiving areas and a smaller increase from other parts of the cortex after $1 \mathrm{hr}$ of continuous retinal stimulation with direct, non-flashing light.

An interesting aspect of the present results is that, while the basal release of $\mathrm{ACh}$ from the sensorimotor cortex is higher than the release from the visual cortex (in agreement with PHILlis, 1968), the content of $\mathrm{ACh}$ in the sensorimotor cortex is about half that of the visual and auditory cortical areas. This implies that either the sensorimotor cortex has a higher turnover of $\mathrm{ACh}$ or a different subcellular compartmentation with better diffusion into the collecting cups. Animals anesthetized with pentobarbital, in order 
to block or greatly reduce the use of cerebral $\mathrm{ACh}$, showed a proportionally greater accumulation of $\mathrm{ACh}$ in the sensorimotor cortex. The increase was 3.5 times in the sensorimotor cortex, while in the motorsensory, auditory and primary visual areas the increase was $2 \cdot 6,3$ and $2 \cdot 4$ times, respectively. It is possible that the low ACh level in the sensorimotor cortex might be due to a potent afferent sensory stimulation occurring at the moment of the animal's decapitation.

\section{REFERENCES}

Bartolini, A. and Pepeu, G. (1967). Investigation into the acetylcholine output from the cerebral cortex of the cat in the presence of hyoscine. Br. J. Pharmac. Chemother. 31: 66-73.

Bartolini, A. and Pepeu, G. (1970). Effect of adrenergic blockers on spontaneous and stimulated acetylcholine output from the cerebral cortex of the cat. Pharmac. Res. Comm. 2: 23-31.

Beani, L., Bianchi, C., Santinoceto, L. and Marchetti, P. (1968). The cerebral acetylcholine release in conscious rabbits with semi-permanently implanted epidural cups. Int. J. Neuropharmac. 7: 469-481.

Belestin, D. and Polak, R. L. (1965). Depression by morphine and chloralose of acetylcholine release from the cat's brain. J. Physiol., Lond. 177: 411-419.

Beleslin, D., Polak, R. L. and Sprovill, D. H. (1965). The release of acetylcholine into the cerebral subarachnoid space of anesthetized cats. J. Physiol., Lond. 177: 420-428.

Bremer, C. and MerRItT, H. H. (1942). Effect of certain choline derivatives on electrical activity in the cortex. Archs Neurol. Psychiat., Chicago 48: 382-395.

Celrsia, G. G. and Jasper, H. H. (1966). Acetylcholine released from cerebral cortex in relation to state of activation. Neurology 16: 1053-1063.

Chorobski, J. and Penfield, W. (1932). Cerebral vasodilator nerves and their pathway from the medulla oblongata. Archs Neurol. Psychiat., Chicago 28: 1257-1289.

COLLIER, B. and MItChELL, J. F. (1966). The central release of acetylcholine during stimulation of the visual pathway. J. Physiol., Lond. 184: 239-254.

Collier, B. and Mitchell, J. F. (1967). The central release of acetylcholine during consciousness and after brain lesions. J. Physiol., Lond. 188: 83-98.

Crossland, J. (1961). Biologic estimation of acetylcholine (Quastel, J. H., Ed.), Method. med. Res. 9: $125-129$.

Deffenu, G., Bartolini, A. and Pepeu, G. (1970). Effect of amphetamine on cholinergic systems of the cerebral cortex of the cat. In: International Symposium on Amphetamines and Related Compounds (Costa, E. and Garrattini, S., Eds.), pp. 357-368. Raven Press, New York.

Dudar, J. D. and Szerb, J. C. (1969). The effect of topically applied atropine on resting and evoked cortical acetylcholine release. J. Physiol., Lond. 203: 741-762.

Elliott, K. A. C., Swank, R. L. and Henderson, N. (1950). Effects of anesthetics and convulsants on the acetylcholine content of brain. Am. J. Physiol. 162: 469-474.

FoG, M. (1935). Om piarteriernes vasomotoriske reaktioner. Levin \& Munksgaard, Copenhagen.

Hemsworth, B. A. and Mrtchell, J. F. (1969). The characteristics of acetylcholine release mechanisms in the auditory cortex. Br. J. Pharmac. Chemother. 36: 161-170.

INGVAR, D. H. (1955). Extraneuronal influences upon the electrical activity of isolated cortex following stimulation of the reticular activating system. Acta physiol. scand. 33: 169-193.

INGVAR, D. H. and SoDerberG, V. (1956). A new method for measuring cerebral blood flow in relation to the electroencephalogram. Electroenceph. Clin. Neurophysiol. 8: 403-412.

IngVaR, D. H. (1958). Cortical state of excitability and cortical circulation. In: Reticular Formation of the Brain (JASPER, H. H. et al., Eds.), pp. 381-400. Little, Brown, Boston.

IngVAR, D. H. and LASSEN, N. A. (1962). Regional blood flow of the cerebral cortex determined by Krypton. Acta physiol. scand. 54: 325-338.

JASPER, H. H. and ERICKSON, T. (1941). Cerebral blood flow and $\mathrm{pH}$ in excessive cortical discharge induced by Metrazol and electrical stimulation. $J$. Neurophysiol. 4: 333-347.

KANAI, T. and SZERB, J. C. (1965). Mesencephalic reticular activating system and cortical acetylcholine output. Nature, Lond. 205: 80-82.

MacINTOSH, F. C. and OrORIN, P. E. (1953). Release of acetylcholine from intact cerebral cortex. Abstr. XIX Int. Physiol. Congr., pp. 580-581.

MCLENNAN, H. (1964). The release of acetylcholine and of 3-hydroxytyramine from the caudate nucleus. J. Physiol., Lond. 174: 152-161.

Miller, F. R., Stavraky, G. W. and Woonton, G. A. (1940). Effects of eserine, acetylcholine and atropine on electrical corticogram. $J$. Neurophysiol. 3: 131-138. 
Mitchell, J. F. (1963). The spontaneous and evoked release of acetylcholine from the cerebral cortex. J. Physiol., Lond. 165: 98-116.

Molenaar, P. C. and Polak, R. L. (1970). Stimulation by atropine of acetylcholine release and synthesis in cortical slices from rat brain. Br. J. Pharmac. Chemother. 40: 406-417.

Murnaghan, M. F. (1958). The morphinized-eserinized leech muscle for assay of acetylcholine. Nature, Lond. 182: 317.

Neal, M. J., Hemsworth, B. A. and Mitchell, J. F. (1968). The excitation of central cholinergic mechanisms by stimulation of the auditory pathway. Life Sci. 7: 757-763.

Pepeu, G. and Bartolini, A. (1968). Effect of psychoactive drugs on the output of acetylcholine from the cerebral cortex of the cat. Eur. J. Pharmac. 4: 254-263.

Philuis, J. W. and ChONG, G. C. (1965). Acetylcholine release from the cerebral and cerebellar cortices: its role in cortical arousal. Nature, Lond. 207: 1253-1255.

Phillis, J. W. (1968). Acetylcholine release from cerebral cortex: its role in cortical arousal. Brain Res. 7: 378-389.

POLAK, R. L. (1965). Effect of hyoscine on the output of acetylcholine into perfused cerebral ventricles of cats. J. Physiol., Lond. 181: 317-323.

POLAK, R. L. (1969). The influence of drugs on the uptake of acetylcholine by slices of rat cerebral cortex. Br. J. Pharmac. Chemother. 36: 144-152.

RoY, C. S. and Sherrington, C. S. (1890). On the regulation of the blood supply of the brain. J. Physial., Lond. 11: 85-108.

Schmid, C. F. and Hendrix, J. P. (1937). The action of chemical substances on cerebral blood vessels. Res. Publs Ass. Res. nerv. ment. Dis. 18; 229-276.

SIE, G., JASPER, H. and WoLfE, L. (1965). Rate of ACh release from cortical surface in encephale and cerveau isolé cat preparations in relation to arousal and epileptic activation of the ECoG. Electroenceph. Clin. Neurophysiol. 18: 206.

Sokuloff, L. and Kety, S. S. (1960). Regulation of cerebral circulation. Physiol. Rev. 40: 38-44.

SoKoloff, L. (1961). Local cerebral circulation at rest and during altered cerebral activity induced by anesthesia or visual stimulation. In: Regional Neurochemistry (KeTY, S. S. and ElkeS, J., Eds.), pp. 107-117. Pergamon Press, Oxford.

Stone, W. E. (1955). Acetylcholine in the brain. 1०. "Free" "bound" and total acetylcholine. Archs Biochem. Biophys. 59: 181-192.

SzERB, J. C. (1963). Acetylcholine-like activity released from brain in vivo. Nature, Lond. 197: 1016.

SZERB, J. C. (1964). The effect of tertiary and quaternary atropine on cortical acetylcholine output and on the electroencephalogram in cats. Can. J. Physiol, Pharmac. 42: 303-314.

SzerB, J. C. (1967). Cortical acetylcholine release and electroencephalographic arousal. J. Physiol., Lond. 192: 329-343. 